NASA

Technical

Paper

2368

September 1984

Characterization of

Erosion of Metallic

Materials Under Cavitation

Attack in a Mineral Oil

Bezzam C. S. Rao

and Donald H. Buckley

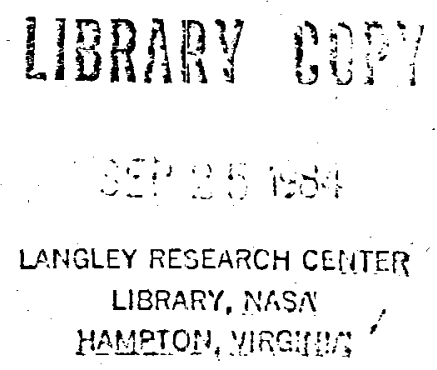



NASA

Technical

Paper

2368

1984

\section{Characterization of Erosion of Metallic Materials Under Cavitation Attack in a Mineral Oil}

Bezzam C. S. Rao and Donald H. Buckley

Lewis Research Center Cleveland, Ohio 



\section{Summary}

Cavitation erosion and erosion rates of eight metallic materials representing three crystal structures were studied. The erosion experiments were conducted with a $20-\mathrm{kHz}$ ultrasonic magnetostrictive oscillator in a viscous mineral oil. The erosion rates of the metals with an fcc matrix were 10 to 100 times higher than that of an hcpmatrix titanium alloy. The erosion rates of iron and molybdenum, with bcc matrices, were higher than that of the titanium alloy but lower than those of the fcc materials. Studies with scanning electron microscopy indicated that the cavitation pits were initially formed at the grain boundaries and precipitates and that the pits that formed at the triple points grew faster than the others. Transcrystalline craters formed by cavitation attack over the surface of grains and roughened the surfaces by multiple slip and twinning. Surface roughness measurements showed that the pits that formed over the grain boundaries deepened faster than other pits. Computer analysis revealed that a geometric expression describes the nondimensional erosion curves during the time period $0.5 t_{0}<t<2.5 t_{0}$ where $t_{0}$ is the incubation period. The fcc metals had very short incubation periods; the titanium alloy had the longest incubation period. The extremely good statistical quantities obtained in the analysis suggested that estimating erosion by using a geometric relationship with nondimensional time will yield reliable values in the time period $0.5 t_{0}<t<2.5 t_{0}$.

\section{Introduction}

Cavitation-the formation, growth, and collapse of vapor bubbles-is known to occur in all liquids and liquid metals in many engineering situations. The occurrence of cavitation in a system has many undesirable effects. The erosion of boundary material is one of these effects that has been faced by the engineering profession over the past 4 or 5 decades. Pumps, turbines, gates, valves, ship propellers, bearings, seals, gears, and many other engineering devices are known to suffer from this phenomenon. The situation may involve a thin layer of liquid, as in lubrication between two surfaces, or a large quantity of flowing liquid, as in flow past a valve or through a turbine. The mechanisms of cavitation attack and material removal are the same in all such situations. Many investigations (e.g., ref. 1) over the past 3 or 4 decades have covered several aspects of the phenomenon that can be broadly classified as the inception, growth, and collapse of vapor bubbles, the pressures generated, and the damage caused to the adjoining boundary materials.

In spite of these investigations, a precise understanding of these subjects has still not been achieved. The highly transient nature of the events and the submicroscopic details of the attack are largely responsible for the difficulties in achieving a complete understanding. In addition, materials differ in their response to cavitation attack. The information available concerning erosion in viscous liquids of engineering importance is very limited. The few attempts to generalize the response of different materials to cavitation attack (refs. 2 to 6 ) had only partial success when a large spectrum of materials was considered and indicated the need for a better understanding of the phenomenon.

This report presents investigations concerning the erosion and erosion rate of different metallic materials in a viscous mineral oil. The materials studied had three crystal structures. The formation and growth of cavitation pits were studied by scanning electron microscopy and surface roughness measurements. Attempts to describe the first two regions of the erosion curves with a generalized mathematical expression are presented.

\section{Experimental Equipment and Test Materials}

The experiments were carried out in an ultrasonic magnetostrictive oscillator (fig. 1) operating at $20-\mathrm{kHz}$ frequency and with a peak-to-peak amplitude of $50 \mu \mathrm{m}$. The test specimens were mounted at the tip of the horn and immersed in the mineral oil. The test specimen vibrated with the horn as it expanded and contracted with the magnetostrictive action of the converter. This action created a low-pressure region and hence caused cavitation of the liquid over the surface of the test specimen. The test specimens for the experiments were prepared from 12.7-mm-diameter rods. Five metals with face-centeredcubic (fcc) matrices, viz aluminum 6061-T6, copper (electrolytic tough pitch), free-cutting brass, phosphor 


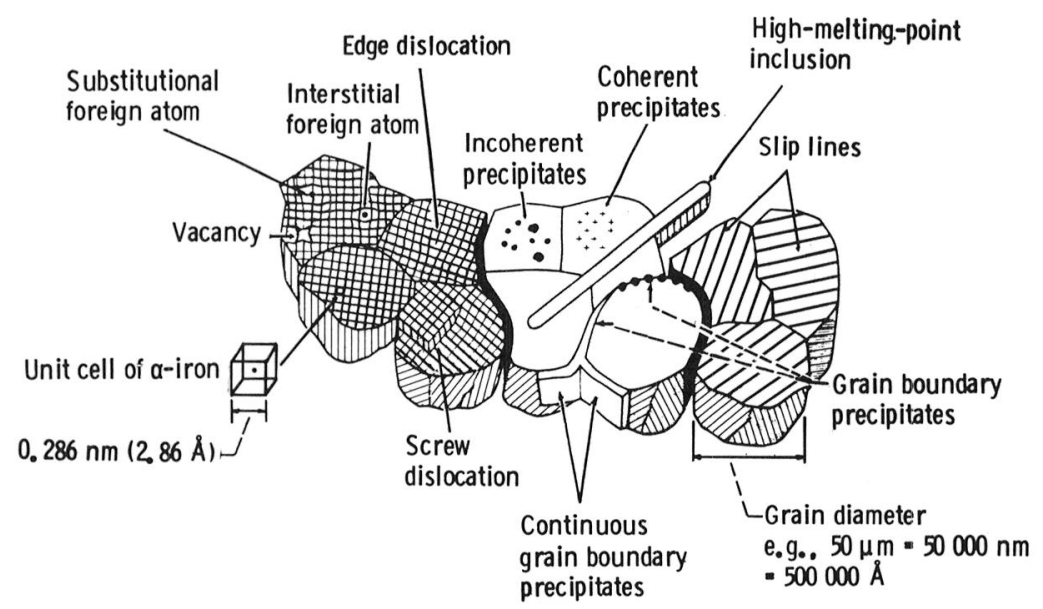

Figure 2.-Structure of a polycrystalline metal based on example of iron. (From ref. 10.)

situations, the microjets are smaller than the grains, and hence each grain is attacked by one or two microjets. Some of the microjets strike over the grain boundaries. Intrusions and extrusions (fig. 3, from ref. 10) are formed depending on the applied stress, the critical resolved shear stress of the material, the orientation of the grain, etc. Some amount of erosion during early attack may also be expected from grain boundary precipitates, point defects, and other surface imperfections.

The applied stress $\sigma$ and the critical resolved shear stress $\tau_{0}$ are related to the shear stress $\tau_{d}$ required to operate a slip source according to the equation

$\tau_{d}=\frac{1}{M}\left(\frac{\sigma}{M}-\tau_{0}\right)\left(\frac{d}{x}\right)^{1 / 2}$

where

$M$ orientation factor, $1 / \sin \phi \cos \lambda$

$d$ average grain diameter

$x \quad$ distance between point of stress and point where slip is to be initiated

$\phi \quad$ angle between slip plane and stress axis

$\lambda \quad$ angle between slip direction and stress axis

In a given cavitation situation, the applied stress $\sigma$ is a constant. The orientation factor $M$ varies with the crystal structure of the material; its average values according to Sach's model are 2.24, 2.0, and 6.5 for fcc, bcc, and hcp polycrystals, respectively. According to Taylor's model $M$ is $\mathbf{3 . 0 6}$ for fcc polycrystals (ref. 11).

If we consider $x$ as a fraction of $d$ in equation (1), we can write

$\tau_{d} \sim \frac{1}{M}\left(\frac{\sigma}{M}-\tau_{0}\right)$
The observation of deformation twins under cavitation attack (refs. 12 and 13) suggests that stacking faults are generated in the material during cavitation attack. Materials with high stacking fault energy $\gamma$ would be expected to erode faster under cavitation attack.

The considerations discussed in the preceding paragraphs indicate that the orientation factor $M$, the critical resolved shear stress $\tau_{0}$, and the stacking fault energy $\gamma$ are very important parameters governing the deformation of metals and alloys under cavitation attack.

\section{Erosion of Materials}

\section{Mean Depth of Penetration}

The erosion of materials is expressed as the mean depth of penetration (MDP) from the surface. The MDP is computed from the mass loss measurements of the test specimens according to the equation

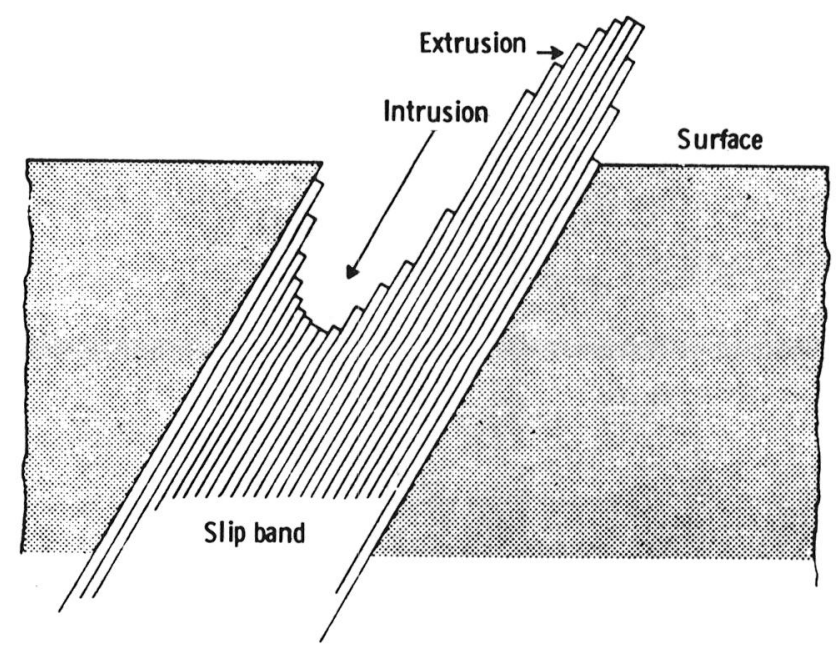

Figure 3.-Formation of extrusions and intrusions in metallic materials. (From ref. 10.) 
$\mathrm{MDP}=\frac{\text { Mass loss per unit area }}{\text { Density }}$

The variation of the mean depth of penetration of the eight metals for a total test time of $40 \mathrm{~min}$ is presented in figure 4 . The erosion on molybdenum and Ti-5Al-2.5Sn was insignificant. The MDP variation of these two materials to a test time of $1800 \mathrm{~min}$ is presented in figure 5 . The MDP of iron is also shown in figure 5 to compare the time scale of erosion with that of the materials presented in figure 4. Copper had the largest MDP (fig. 4) and Ti-5Al-2.5Sn had the smallest MDP (fig. 5). The other

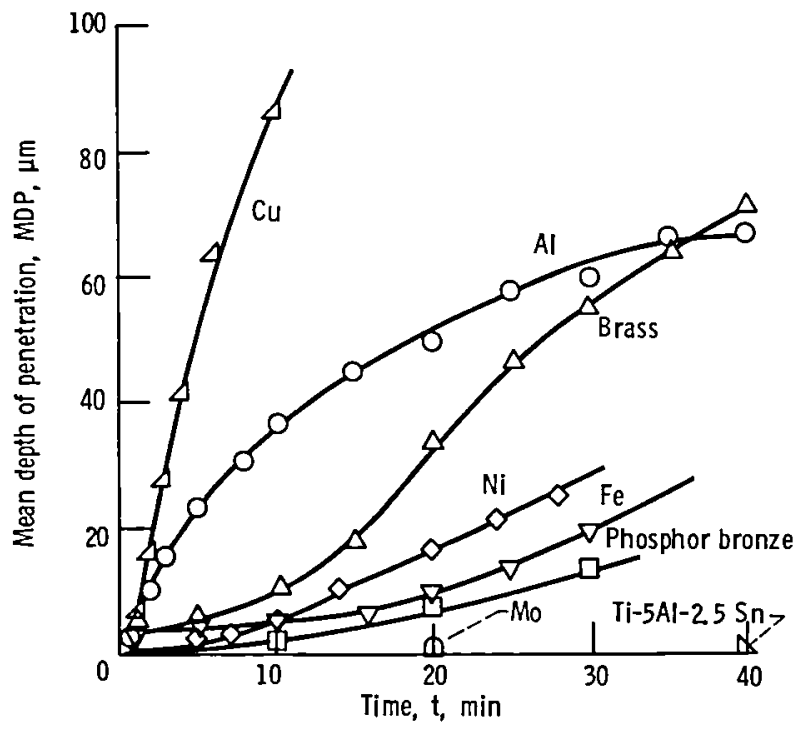

Figure 4.-Variation of mean depth of penetration with time-short test time. metals Al 6061-T6, brass, nickel, iron, phosphor bronze, and molybdenum had intermediate MDP's in decreasing order of magnitude.

The variation and average values of the mean depth of penetration rate (MDPR) with time were plotted for the eight metals. The average MDPR of the fcc group (fig. 6(a)) varied from $26.4 \mu \mathrm{m} / \mathrm{hr}$ for phosphor bronze to $542.3 \mu \mathrm{m} / \mathrm{hr}$ for copper. The average MDPR's for iron and molybdenum (fig. 6(b)) were 43 and $1.95 \mu \mathrm{m} / \mathrm{hr}$, respectively; that for $\mathrm{Ti}-5 \mathrm{Al}-2.5 \mathrm{Sn}$ (fig. $6(\mathrm{c})$ ) was 0.5 $\mu \mathrm{m} / \mathrm{hr}$. The MDPR's of the fcc group were 10 to 100 times higher than the erosion rate of the hcp-matrix material Ti-5Al-2.5Sn. Similarly, the MDPR's of iron and molybdenum (bcc matrices) were higher than the erosion rate of Ti-5Al-2.5Sn. The MDPR's of both fcc and hcp materials in general peaked and then decreased. Ti-5Al-2.5Sn had periods of low or insignificant MDPR followed by periods of high MDPR (fig. 6(c)). For the bcc materials (fig. 6(b)) the MDPR increased steadily as the test duration increased. The experiments on these materials could not be carried out for a longer duration because the specimens broke from the horn.

\section{Scanning Electron Microscopy Observations}

To clarify the processes of deformation and material removal under cavitation attack, the eroded surfaces were examined with a scanning electron microscope. Micrographs presented in figure 7 show the different stages of these processes for $\mathrm{Cu}-35.5 \mathrm{Zn}-3 \mathrm{~Pb}$ brass. On the undamaged, lightly etched surface (fig. $7(\mathrm{a})$ ) the lead phase is evident from the dark spots over the grain boundaries. The eroded surface at $10 \mathrm{sec}$ (fig. 7(b)) shows the formation of tiny cavitation pits over the grain

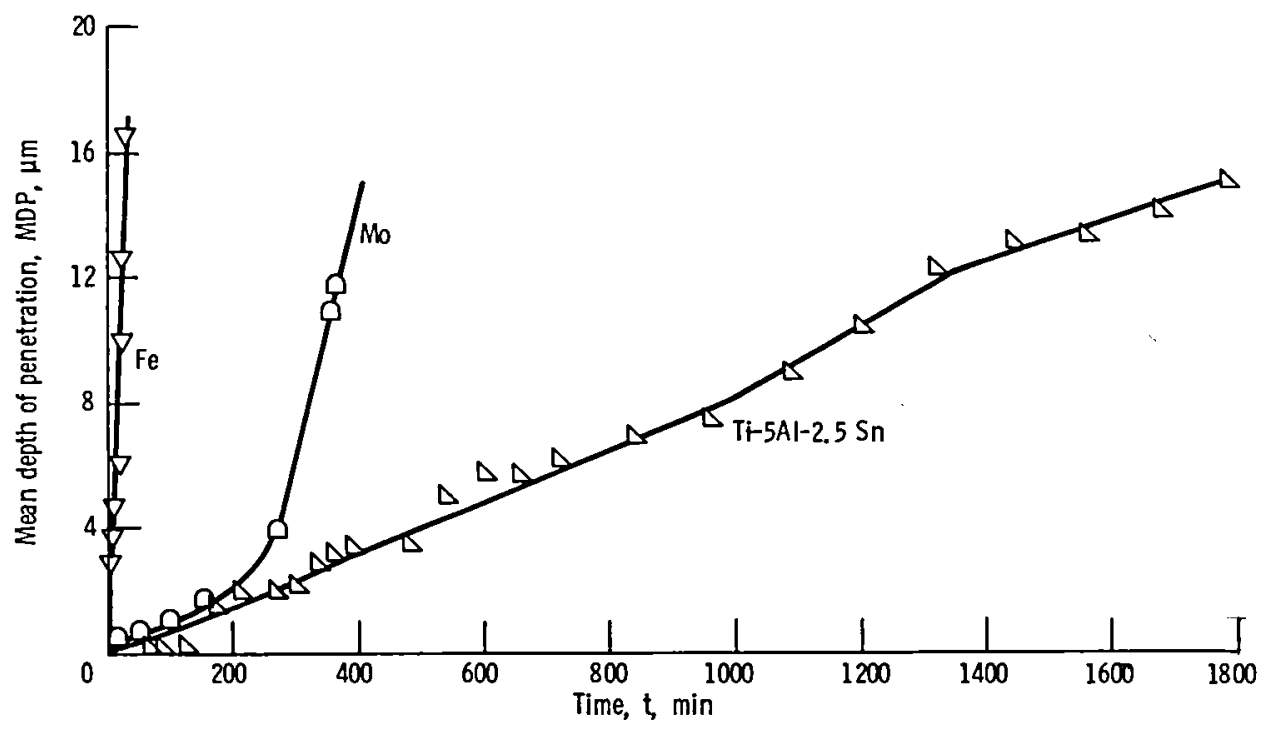

Figure 5.-Variation of mean depth of penetration with time-long test time. 

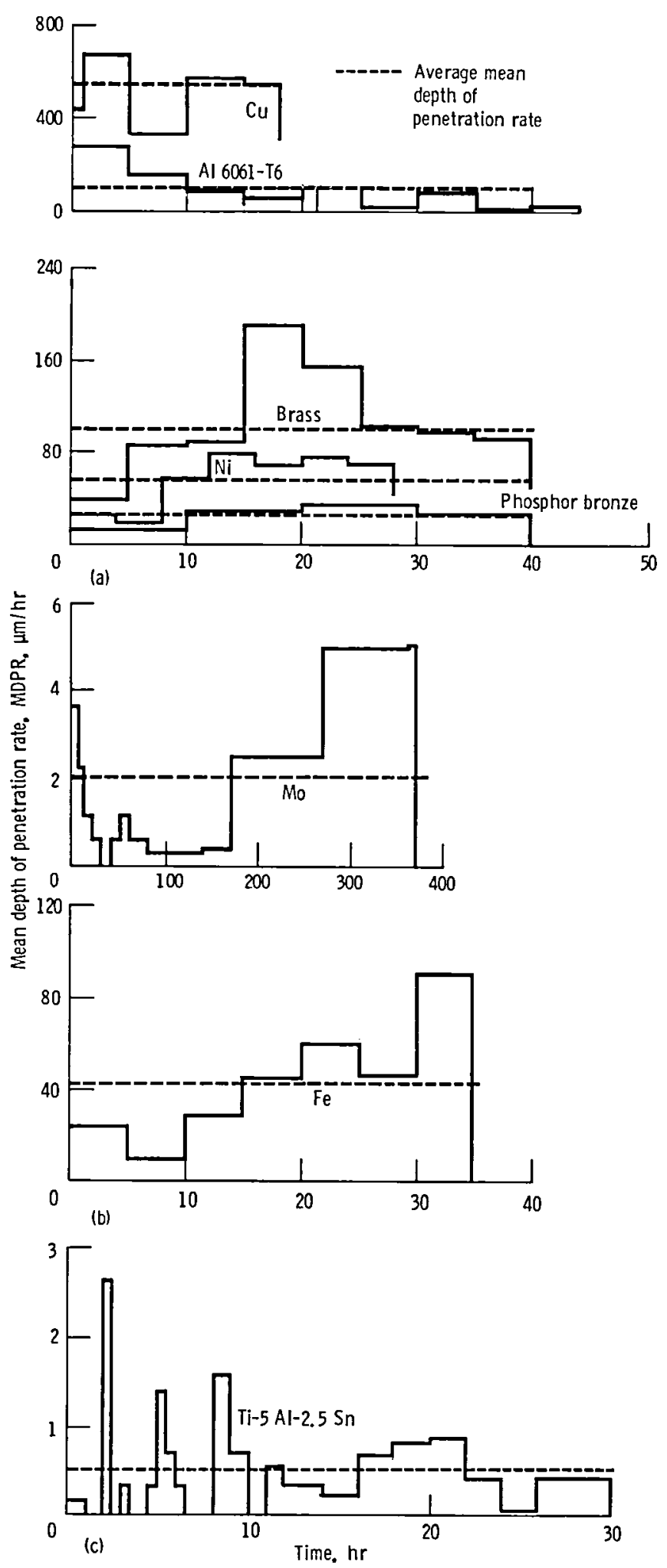

(a) fcc matrices.

(b) bcc matrices.

(c) hep matrix.

Figure 6.-Variation of mean depth of penetration rate with time. boundaries and precipitates. The eroded surface at $20 \mathrm{sec}$ (fig. 7(c)) shows further cavitation attack over the grain boundaries and plastic deformation of the grains involving slip. The eroded surface at $30 \mathrm{sec}$ (fig. 7(d)) shows growth in the size of cavitation pits at the triple points and the formation of deformation twins. The eroded surface at $40 \mathrm{sec}$ (fig. 7(e)) shows material removal by fragmentation of the grain. The fragmented particle is bounded by the grain boundaries and possibly a twin plane. An indentation due to the possible impact of a microjet can also be seen above the fragmented particle. The eroded surface at $60 \mathrm{sec}$ (fig. 7(f)) shows a considerable amount of deformation and the formation of large craters on the surface grains.

Figure 8 presents magnified views of individual cavitation pits at different stages of cavitation attack. Figures 8(a), (b), and (c) are magnified views of figures 7(c), (d), and (e), respectively. Figures $8(a)$ and (b) show cavitation pit growth caused by cutting action along the grain boundaries and through specific planes in the grains. Note that the cutting action into the grain resulted in progressive slip and twinning across the grain. Figure 8(c) shows clearly the details of the fragmented particle and the indentation on its surface. Figure 8(d) presents the development of a transcrystalline crater.

The investigations using scanning electron microscopy, in general, revealed that cavitation pits were initially formed over the grain boundaries and other precipitates. The pits that formed at the triple points (where three grain boundaries meet) appeared to grow faster than the other pits by cutting action along the grain boundaries and into the grain. Multiple slip and twinning occurred across the grains. Part of the grains close to the triple points eroded by fragmentation. Cavitation attack over the surface of grains that had been roughened by multiple slip and twinning formed transcrystalline craters. The nature of the indentations over the surface and the pits formed suggested the cylindrical impact of a microjet during cavitation attack rather than the spherical impact of a shock wave.

\section{Surface Roughness Measurements}

The variations in surface roughness during cavitation attack were studied by taking surface profiles at different intervals. Comparing two typical profiles of the Ti-5Al-2.5Sn surface at 660 and $1440 \mathrm{~min}$ (fig. 9) with the micrographs presented in figures 7 and 8 suggested that the deep pits in the surface profiles were located over the grain boundaries. They deepened faster than the craters formed over grain surfaces. The maximum depths $h_{\max }$ of the pits in the surface profiles were 6 and $10 \mu \mathrm{m}$ at 660 and $1440 \mathrm{~min}$, respectively. The MDP obtained from mass loss measurements at these two times were 5.7 

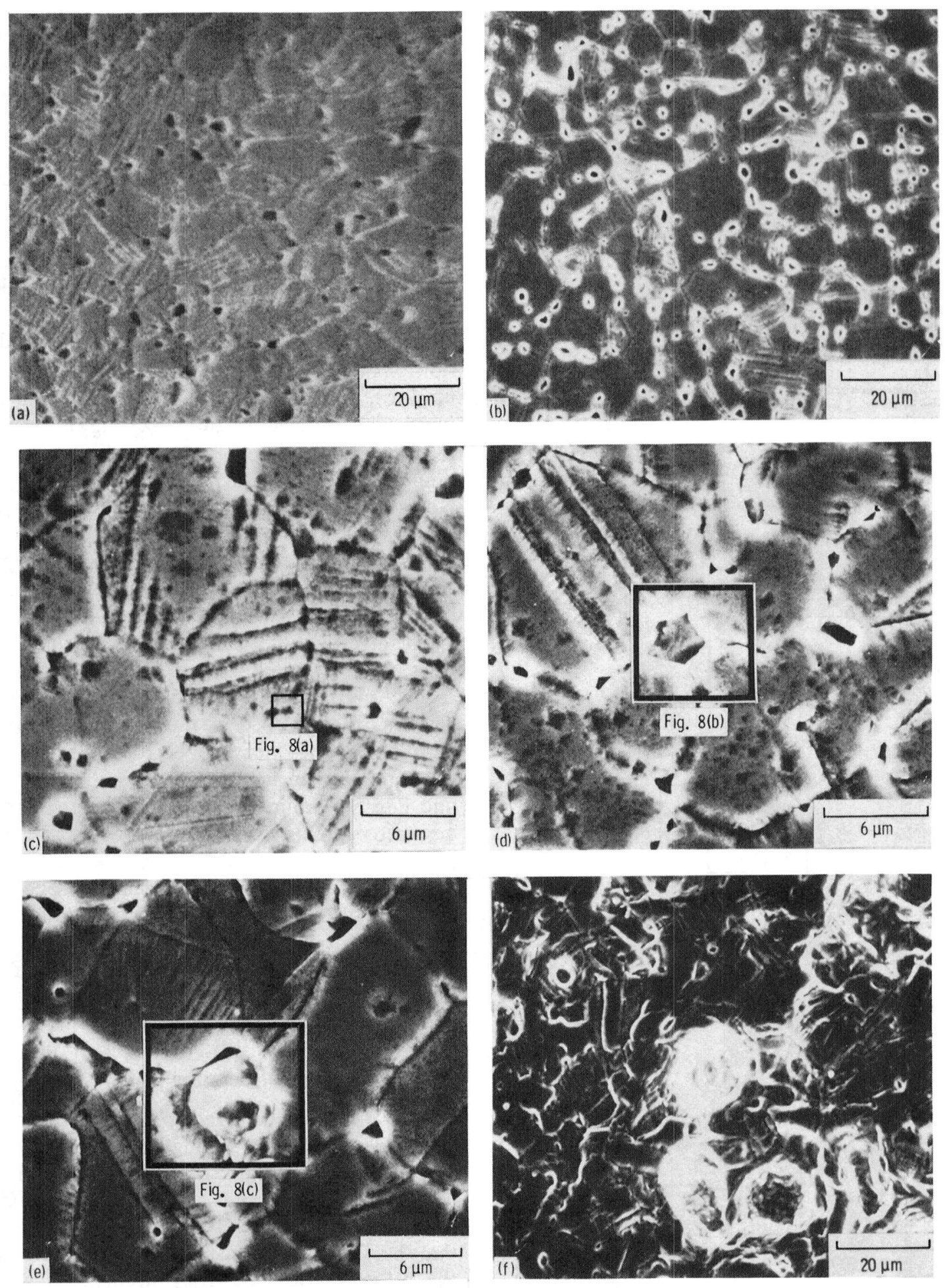
(a) Undamaged.
(b) $t=10 \mathrm{sec}$.
(c) $t=20 \mathrm{sec}$.
(d) $t=30 \mathrm{sec}$
(e) $t=40 \mathrm{sec}$.
(f) $t=60 \mathrm{sec}$.

Figure 7.-SEM micrographs of brass surface. 

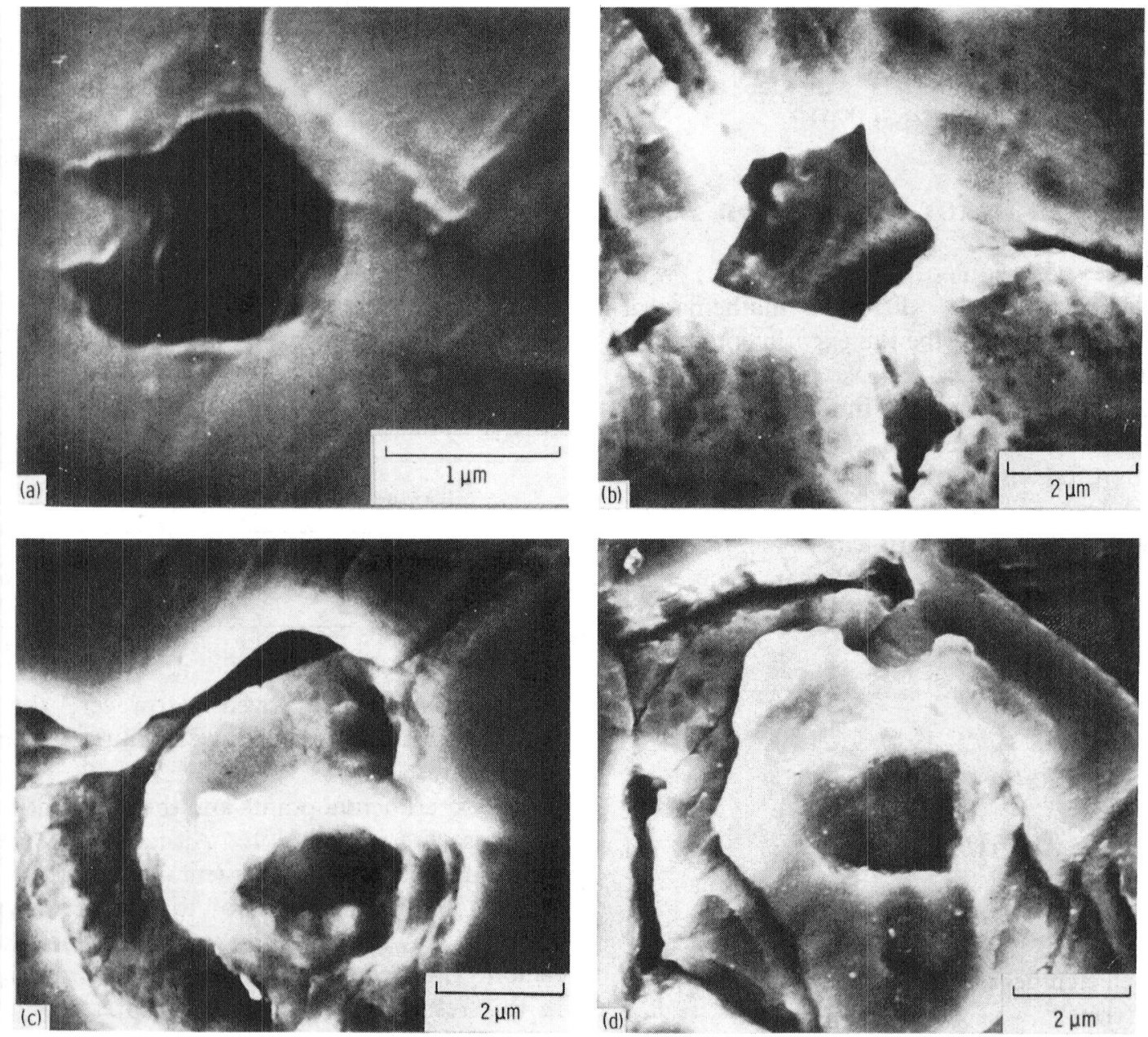
(a) $t=20 \mathrm{sec}$.
(c) $t=40 \mathrm{sec}$.
(b) $t=30 \mathrm{sec}$.
(d) $t=60 \mathrm{sec}$.

Figure 8.-Magnified views of cavitation attack on brass surface.

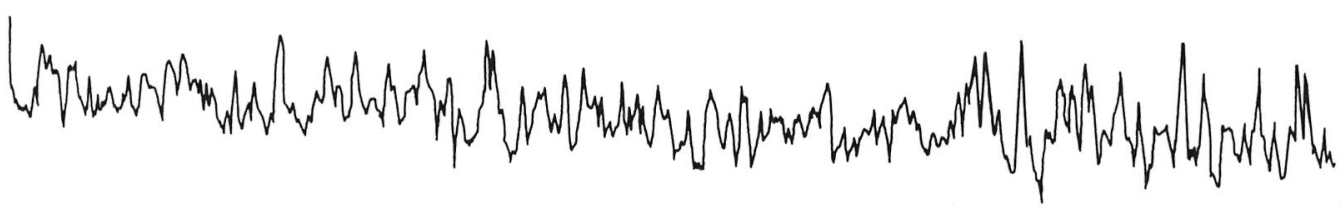

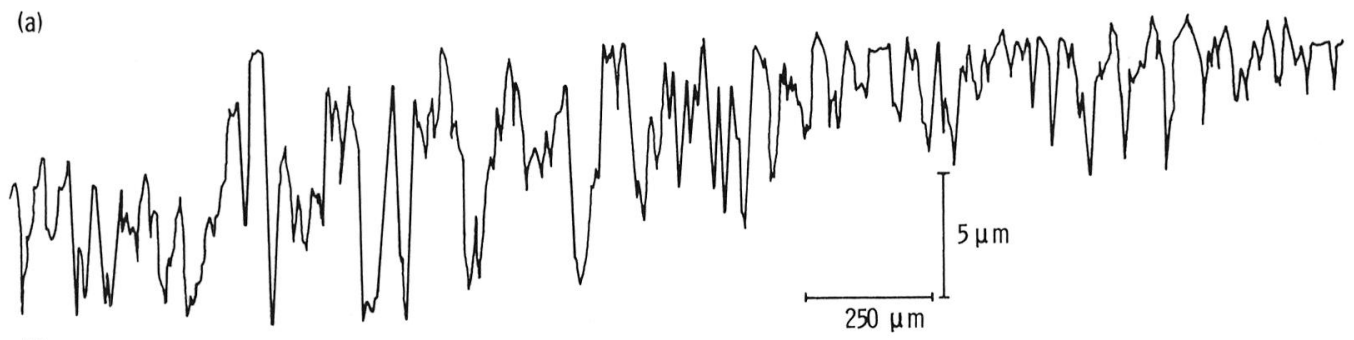

(b)

(a) $t=660 \mathrm{~min}$. Maximum pit depth, $h_{\max }, \sim 6 \mu \mathrm{m}$.

(b) $t=1440 \mathrm{~min}$. Maximum pit depth, $h_{\max }, \sim 9.5 \mu \mathrm{m}$.

Figure 9.-Surface profiles of Ti-5Al-2.5Sn specimen. 
and $13.1 \mu \mathrm{m}$, respectively. For the titanium alloy, the two quantities $h_{\max }$ and MDP were of comparable magnitude. But for the materials with fcc and bcc matrices, $h_{\max }$ was much larger than MDP.

\section{Fitting an Equation for the Erosion Data}

To clarify the variation of erosion (MDP) with increasing cavitation attack, different mathematical expressions were used to describe the experimental data. This was achieved by using a "curve fitter" program developed by Interactive Microware Inc. (ref. 14) with an Apple II personal computer. This program can fit an equation by either interpolation or least-squares techniques. A least-squares technique is the most reasonable approach for the type of experimental data in this study. With this program either linear, geometric, exponential, or polynomial expressions can be fitted. The different forms of these expressions are

Linear: $\quad y=A x$

Geometric: $\quad y=A x^{B}$

Exponential: $\quad y=A \exp (B x)$, or $A e^{B x}$

Polynomial: $\quad y=A+B x+C x^{2}+\cdots+P x^{n}$

where $n$ is the selected degree of the equation and $n+1$ is the number of terms.

The erosion curves presented in figures 4 to 6 indicate three regions, viz (1) an initial region of very low or insignificant erosion rate; (2) a region of increasing erosion rate; and (3) a region of decreasing erosion rate. The erosion curves of iron and molybdenum show only the first two regions. The initial region is generally termed the "incubation period." The decreasing erosion rate, in the third region, is perhaps due to the impact pressures of the microjets or shock waves being attenuated in traveling longer distances as erosion progresses.

\section{Analysis Using Dimensional Data}

In attempting to describe the erosion curves by known mathematical expressions, the dimensional plots of MDP versus time and equations (2) and (4) were first considered. As an example, the erosion curve for brass was examined. A geometric expression of the type given in equation (2) was fitted for the erosion data spanning the three regions just described. The relative merits of the equations were judged from the statistical parameters, viz the coefficient of determination $C D$, the coefficient of correlation $\mathrm{CC}$, and the standard error of estimate $\mathrm{SE}$ (table III(a)). Next, polynomials of degrees 2, 3, and 4 were fitted (table III(a)). These quantities indicate that as the degree of the polynomial increased from 2 to 4 ,
TABLE III.-STATISTICAL QUANTITIES FOR ANALYSIS OF EROSION DATA OF BRASS

(a) Complete erosion data

\begin{tabular}{|c|c|c|c|}
\hline $\begin{array}{c}\text { Type of } \\
\text { correlation }\end{array}$ & $\begin{array}{c}\text { Coefficient of } \\
\text { determination, } \\
\text { CD }\end{array}$ & $\begin{array}{c}\text { Coefficient of } \\
\text { correlation, } \\
\text { CC }\end{array}$ & $\begin{array}{c}\text { Standard error } \\
\text { of estimate, } \\
\text { SE }\end{array}$ \\
\hline $\begin{array}{l}\text { Geometric } \\
\text { Polynomial of } \\
\text { degree 2 }\end{array}$ & 0.990 & 0.995 & 0.116 \\
$\begin{array}{c}\text { Polynomial of } \\
\text { degree 3 }\end{array}$ & .990 & .995 & 3.032 \\
$\begin{array}{c}\text { Polynomial of } \\
\text { degree 4 }\end{array}$ & .998 & .999 & 1.979 \\
\hline
\end{tabular}

(b) For erosion data with $2 \mu \mathrm{m}<\mathrm{MDP}<25 \mu \mathrm{m}$

\begin{tabular}{|l|r|r|r|}
\hline $\begin{array}{l}\text { Geometric } \\
\text { Polynomial of } \\
\text { degree 2 }\end{array}$ & 0.996 & 0.998 & 0.055 \\
& .997 & .999 & .676 \\
\hline
\end{tabular}

the correlations improved. However, the geometric relationship indicates the lowest value of standard error of estimate.

The experimental points and the different fitted curves are presented in figure 10. Although the fourth-degree polynomial fit the experimental data very well in the second and third regions of the erosion curves, it was completely away from the experimental points in the first region. The second-degree polynomial was slightly better in this respect. The geometric expression followed the experimental points closest through all the regions, especially the first and second. For the materials examined herein, the second stage ended at an MDP of approximately $25 \mu \mathrm{m}$.

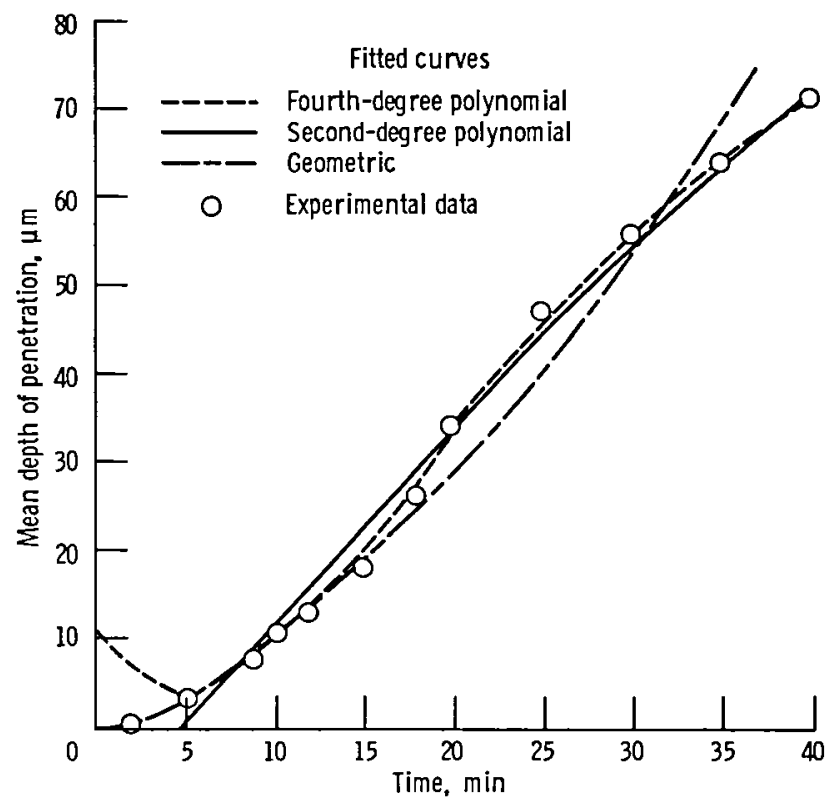

Figure 10.-Variation of fitted curves and experimental data for brass. 
In the next step in the analysis, experimental data involving MDP of $25 \mu \mathrm{m}$ or less were considered. Ignoring the first one or two experimental points at the very beginning of the incubation period resulted in improved statistical quantities (table III(b)). The equations obtained were

$\mathrm{MDP}=0.302 t 1.54$

$\mathrm{MDP}=0.779+0.343 t+0.059 t^{2}$

An examination of the values in table III indicates that the standard error of estimate was improved considerably by restricting the erosion data to an MDP less than $25 \mu \mathrm{m}$. The geometric expression involving one unknown coefficient and one unknown exponent had a standard error of estimate that was 12 times smaller than that for a second-degree polynomial involving three unknown coefficients.

Table IV presents the equations obtained and the corresponding statistical quantities for the eight metals examined. The statistical quantities indicate that a geometric relationship describes the erosion curves in the first two regions for MDP less than $25 \mu \mathrm{m}$ very well. The values of coefficients and exponents obtained are interesting. The Ti-5Al-2.5Sn alloy, with an hep matrix, had a very small coefficient and the smallest exponent in the group. Molybdenum, with a bcc matrix, had the smallest coefficient and the largest exponent. In the materials with fcc matrices, copper had the largest coefficient and the smallest exponent, but nickel had the smallest coefficient and the largest exponent. These trends are discussed further in the next section.

\section{Analysis Using Nondimensional Data}

To generalize the variation of erosion on different materials, it is necessary to use nondimensional experimental data. In the present analysis, the incubation period $t_{0}$ and the corresponding mean depth of penetration (MDPO) of the different materials were used to nondimensionalize the time $t$ and the MDP, respectively. The nondimensional quantities can be expressed as

$\mathrm{MDPN}=\frac{\mathrm{MDP}}{\mathrm{MDPO}}$

$T=\frac{t}{t_{0}}$

The incubation period $t_{0}$ is generally defined in three ways, viz (1) the duration of a test in which no mass loss occurs; (2) the intercept on the time axis as the linear part of the erosion curve is extended to it; and (3) the duration of a test for obtaining a defined value of MDP (e.g., $2 \mu \mathrm{m}$ or $5 \mu \mathrm{m}$ ). The first definition is mostly hypothetical because the erosion of precipitates and other surface defects is known to occur in relatively insignificant periods of cavitation attack. In the present analysis incubation periods defined according to the second and third definitions were used. The analysis using the incubation periods that corresponded to an MDP of $5 \mu \mathrm{m}$, according to the third definition, resulted in better statistical quantities than the analysis using incubation periods obtained according to the second definition. The analysis using nondimensional erosion data involving incubation periods corresponding to an MDP of $5 \mu \mathrm{m}$ is described in the following paragraphs.

The incubation periods $t_{0}$ of the eight materials, the equations obtained with these values, and the corresponding statistical quantities $\mathrm{CD}, \mathrm{CC}$, and SE are presented in table V. Small changes in the values of $t_{0}$ were made in the analysis in order to make the coefficients in the equations as close to unity as possible. For the materials examined in this study the fcc metals had very short incubation periods (fig. 11), molybdenum (bcc matrix) had a longer period, and the titanium alloy (hcp matrix) had the longest period. An examination of the statistical quantities in table $\mathrm{V}$ indicates that a geometric equation of the type of equation (2) describes

TABLE IV.-BEST-FITTING EQUATIONS AND STATISTICAL

QUANTITIES FOR MDP LESS THAN $25 \mu \mathrm{m}$

\begin{tabular}{|l|c|c|c|c|}
\hline \multicolumn{1}{|c|}{ Material } & $\begin{array}{c}\text { Best-fitting } \\
\text { equation, } \\
\text { MDP }=A t^{B}\end{array}$ & $\begin{array}{c}\text { Coefficient of } \\
\text { determination, } \\
\text { CD }\end{array}$ & $\begin{array}{c}\text { Coefficient of } \\
\text { correlation, } \\
\text { CC }\end{array}$ & $\begin{array}{c}\text { Standard } \\
\text { error of } \\
\text { estimate, } \\
\text { SE }\end{array}$ \\
\hline Al 6061-T6 & $3.03 t^{1.59}$ & 0.939 & 0.969 & 0.225 \\
Cu (ETP) & $7.91 t^{1.08}$ & .984 & .992 & .100 \\
Brass & $.302 t^{1.54}$ & .996 & .998 & .055 \\
Phosphor bronze & $.138 t^{1.32}$ & .977 & .989 & .196 \\
Nickel & $.048 t^{2.03}$ & .999 & .999 & .025 \\
Iron & $.124 t^{1.42}$ & .990 & .995 & .101 \\
Molybdenum & $2.23 \times 10^{-6} t^{2.6}$ & .979 & .989 & .170 \\
Ti-5Al-2.5Sn & $8.06 \times 10^{-3} t^{1.0}$ & .985 & .993 & .092 \\
\hline
\end{tabular}


TABLE V.-INCUBATION PERIODS, BEST-FITTING EQUATIONS, AND STATISTICAL QUANTITIES

\begin{tabular}{|l|c|c|c|c|c|}
\hline \multicolumn{1}{|c|}{ Material } & $\begin{array}{c}\text { Incubation } \\
\text { period, } \\
t_{0}, \\
\text { min }\end{array}$ & $\begin{array}{c}\text { Best-fitting } \\
\text { equation, } \\
\text { MDPN }=A T^{B}\end{array}$ & $\begin{array}{c}\text { Coefficient of } \\
\text { determination, } \\
\text { CD }\end{array}$ & $\begin{array}{c}\text { Coefficient of } \\
\text { correlation, } \\
\text { CC }\end{array}$ & $\begin{array}{c}\text { Standard } \\
\text { error of } \\
\text { estimate, } \\
\text { SE }\end{array}$ \\
\hline Al 6061-T6 & 1.3 & $0.995 T^{1.01}$ & 0.998 & 0.999 & 0.025 \\
Cu (ETP) & .67 & $.995 T^{1.14}$ & .992 & .996 & .100 \\
Brass & 6.2 & $1.001 T^{1.52}$ & .994 & .997 & .059 \\
Phosphor bronze & 16.5 & $.998 T^{1.54}$ & .993 & .996 & .077 \\
Nickel & 10.2 & $.991 T^{1.73}$ & .992 & .996 & .083 \\
Iron & 14 & $.999 T^{1.76}$ & .998 & .999 & .044 \\
Molybdenum & 270 & $1.001 T^{2.55}$ & .994 & .997 & .068 \\
Ti-5Al-2.5Sn & 600 & $1.004 T^{1.03}$ & .984 & .992 & .081 \\
\hline
\end{tabular}

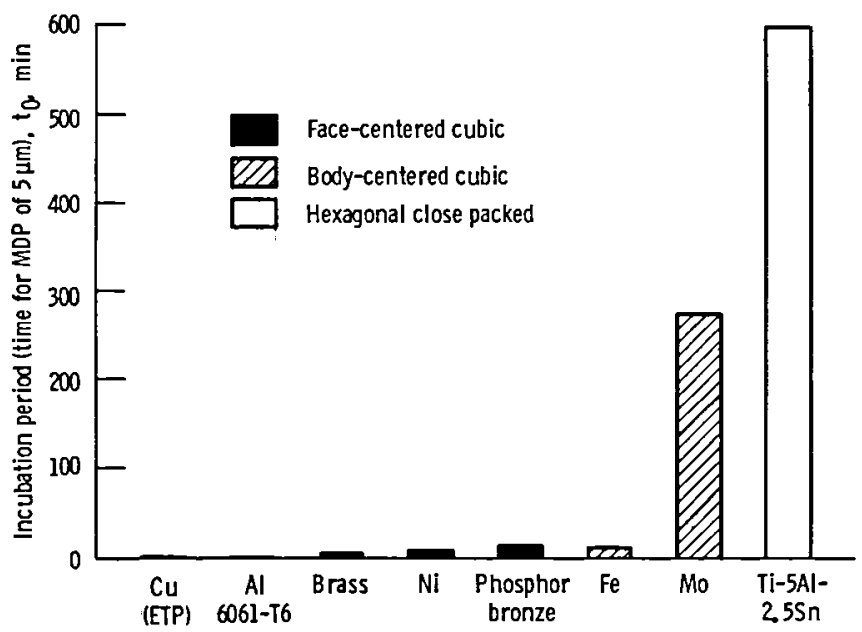

Figure 11.-Incubation periods of the metals studied.

the erosion curves extremely well in the period $0.5 t_{0}<t<2.5 t_{0}$.

A plot of the nondimensional quantities MDPN and $T$ (fig. 12) shows that molybdenum (bcc matrix) eroded fastest in relation to its incubation period and that copper and aluminum ( $\mathrm{fcc}$ matrices) and titanium (hcp matrix) eroded at considerably slower rates. The same conclusion can be reached by examining the exponents in the best correlating equations presented in table V. These investigations show that the materials with fcc matrices in general had short incubation periods. Therefore most of these materials eroded quickly under cavitation attack. The materials with hcp matrices had long incubation periods and eroded most slowly. The materials with bcc matrices had high erosion rates although they had long incubation periods. Hence, materials with hcp matrices need more detailed investigation to characterize their behavior under cavitation attack and to exploit their strength in cavitation situations.

The extremely good statistical quantities in table $\mathrm{V}$ suggest that estimating MDPN by using a geometric

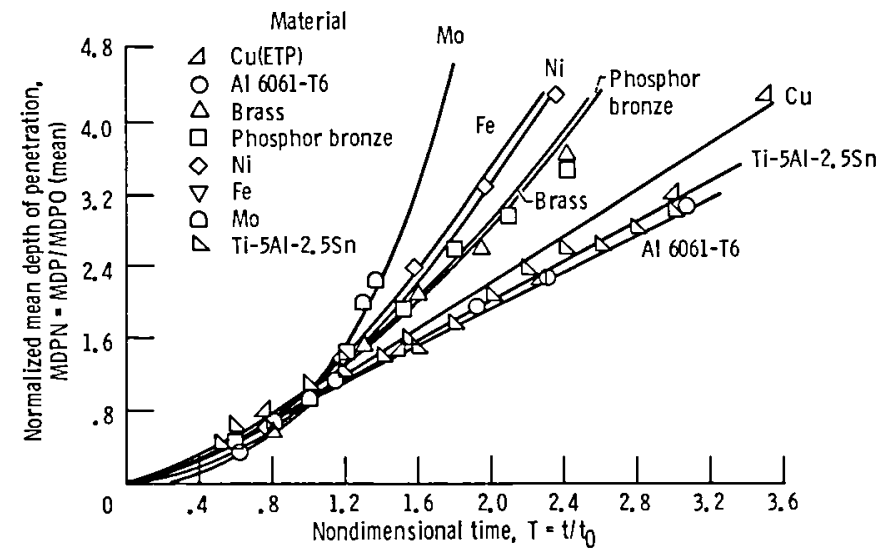

Figure 12.-Variation of nondimensional mean depth of penetration with nondimensional time.

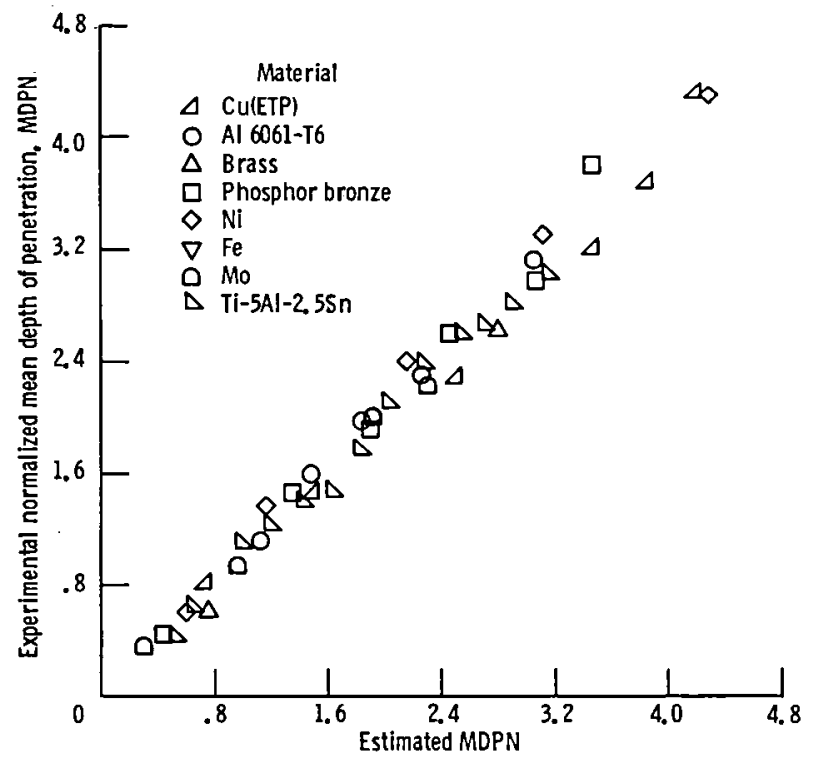

Figure 13.-Experimental mean depth of penetration as function of estimated MDPN.

expression will yield very reliable values in the period $0.5 t_{0}<t<2.5 t_{0}$. A plot of experimental values of MDPN versus estimated values (fig. 13) also shows an extremely good curve fit. 


\section{Conclusions}

The erosion of eight metallic materials due to cavitation attack in a mineral oil was studied. Variations in mean depth of penetration, surface roughness, and microstructure were investigated. From these investigations, the following conclusions were drawn:

1. The erosion rates of the fcc-matrix materials were 10 to 100 times higher than the erosion rate of a titanium alloy (hcp matrix). The erosion rates of iron and molybdenum (bcc matrices) were higher than that of the titanium alloy but lower than those of the fec group.

2. The erosion rates of both fcc and hcp materials in general indicated a peak rate and then a decreasing trend. Also the erosion of the titanium alloy had periods of low or insignificant mean depth of penetration rate (MDPR) followed by periods of high MDPR. The erosion rate of bcc materials increased with time.

3. Investigations using scanning electron microscopy indicated that cavitation pits were initially formed over the grain boundaries and other precipitates. Part of the grains close to the triple points eroded by fragmentation. Transcrystalline craters formed by cavitation attack over the surface grains that had been roughened by multiple slip and twinning.

4. Measurement of the variations in surface roughness during cavitation attack indicated that the pits that formed over the grain boundaries deepened faster than the other pits. The maximum depth of the pits was generally greater than the MDP obtained from mass loss measurements.

5. A geometric expression such as $\mathrm{MDPN}=A T^{B}$ fitted the nondimensional experimental data of the eight materials very well in the range $0.5 t_{0}<t<2.5 t_{0}$, where $t_{0}$ is the incubation period. The fcc materials had very short incubation periods, the bcc materials had longer incubation periods, and the titanium alloy had the longest incubation period.

National Aeronautics and Space Administration

Lewis Research Center

Cleveland, Ohio, June 19, 1984

\section{References}

1. Hammitt, Frederick Gnichtel: Cavitation and Multiphase Flow Phenomena. McGraw Hill Book Co., Inc., 1980, pp. 220-291.

2. Thiruvengadam, A., A Unified Theory of Cavitation Damage. J. Basic Eng., vol. 85., no. 3, Sept. 1963, pp. 365-376.

3. Garcia, R.; and Hammitt, F.G., Cavitation Damage and Correlations with Material and Fluid Properties. J. Basic Eng., vol. 89, no. 4, Dec. 1967, pp. 753-763.

4. Rao, B.C. Syamala; Rao, N.S. Lakshmana; and Seetharamiah, K.: Cavitation Erosion Studies with Venturi and Rotating Disk in Water. J. Basic Eng., vol. 92, no. 3, Sept. 1970, pp. 563-579.

5. Rao, B.C. Syamala; Rao, P. Veerabhadra; and Rao, N.S. Lakshmana: Evaluation of Erosion Resistance of Metallic Materials and the Role of Material Properties in Correlations. J. Test. Eval., vol. 7, no. 3, May 1979, pp. 133-146.

6. Kristensen, J. Klaestrup; Hansson, I.; and Morch, K.A.: A Simple Model for Cavitation Erosion of Metals. J. Phys. D, vol. 11, no. 6, April 21, 1978, pp. 899-912.

7. Shima, A.; Takayama, K.; Tomita, Y.; and Ohsawa, N.: Mechanism of Impact Pressure Generation from Spark-Generated Bubble Collapse Near a Wall. AIAA J., vol. 21, no. 1, Jan. 1983, pp. 55-59.

8. Lauterborn, W.; and Bolle, H.: Experimental Investigation of Cavitation-Bubble Collapse in Neighborhood of a Solid Boundary. J. Fluid Mech., vol. 72, Nov. 1975, pp. 391-399.

9. Rao, Bezzam C.S.; and Buckley, Donald H.: Cavitation Pitting and Erosion of Aluminum 6061-T6 in Mineral Oil and Water. NASA TP-2146, 1983.

10. Tegart, W.J.M.: Elements of Mechanical Metallurgy, Macmillan, 1966, pp. 99-193.

11. Engel, L.; and Klingele, H.: An Atlas of Metal Damage. Wolfe Publishing Ltd. (London), 1981.

12. Rao, B.C.S.; and Buckley, D.H.: Deformation and Erosion of FCC Metals and Alloys Under Cavitation Attack. Mater. Sci. Eng., vol. 66, 1984.

13. Pedersen, T. Fich; Pedersen, S.; and Hansson, I.: Sub-surface Deformation Studies of Cavitation Eroded FCC Materials. Proceedings of 6th International Conference on Erosion by Liquid and Solid Impact, J. E. Field and N. S. Corney, eds., Cavendish Laboratory, Cambridge (England), 1983, pp. 4-1 to 4-7.

14. Warme, Paul K.: Curve Fitter. Interactive Microware Inc., State College, Pa., 1980. 




\begin{tabular}{|c|c|c|}
\hline \multicolumn{2}{|l|}{$\begin{array}{l}\text { 1. Report No. } \\
\text { NASA TP-2368 }\end{array}$} & 3. Recipient's Catalog No. \\
\hline \multirow{2}{*}{\multicolumn{2}{|c|}{$\begin{array}{l}\text { 4. Title and Subtitle } \\
\text { Characterization of Erosion of Metallic Materials } \\
\text { Under Cavitation Attack in a Mineral } 0 \text { il }\end{array}$}} & $\begin{array}{l}\text { 5. Report Date } \\
\text { September } 1984\end{array}$ \\
\hline & & $\begin{array}{l}\text { 6. Pertorming Organization Code } \\
506-53-1 B\end{array}$ \\
\hline \multicolumn{2}{|l|}{ 7. Author(s) } & $\begin{array}{l}\text { 8. Performing Organization Report No. } \\
\text { E-2049 }\end{array}$ \\
\hline \multicolumn{2}{|l|}{ Bezzam C. S. Rao and Donald H. Buckley } & 10. Work Unit No. \\
\hline \multicolumn{2}{|l|}{ 9. Performing Organization Name and Address } & \\
\hline \multicolumn{2}{|l|}{$\begin{array}{l}\text { National Aeronautics and Space Administration } \\
\text { Lewis Research Center } \\
\text { Cleveland, Ohio } 44135\end{array}$} & 11. Contract or Grant No. \\
\hline \multicolumn{2}{|l|}{ 12. Sponsoring Agency Name and Address } & Technical Paper \\
\hline \multicolumn{2}{|l|}{$\begin{array}{l}\text { National Aeronautics and Space Administration } \\
\text { Washington, D.C. } 20546\end{array}$} & 14. Sponsoring Agency Code \\
\hline \multicolumn{3}{|c|}{$\begin{array}{l}\text { Bezzam C. S. Rao, Indian Institute of Science, Bangalore, India, and National } \\
\text { Research Council - NASA Research Associate; Donald H. Buckley, Lewis Research } \\
\text { Center. }\end{array}$} \\
\hline \multicolumn{3}{|c|}{ 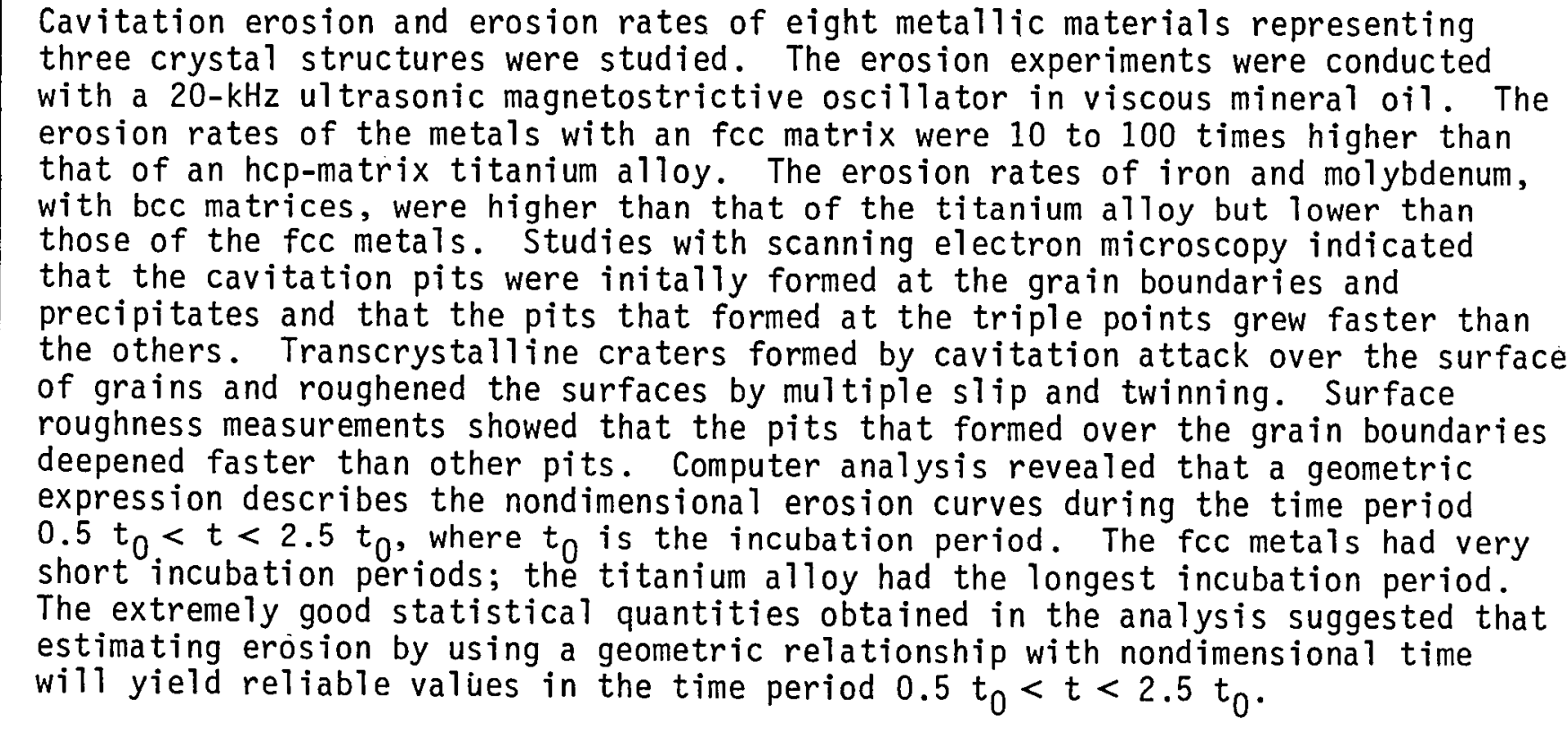 } \\
\hline \multicolumn{3}{|l|}{ 17. Key Words (Suggested by Author(s)) } \\
\hline $\begin{array}{l}\text { Cavitation erosion; Mineral oil; Crystal } \\
\text { structure; Scanning electron microscopy; } \\
\text { Computer correlations }\end{array}$ & & \\
\hline $\begin{array}{r}\text { 19. Security Classif. (of this report) } \\
\text { Unclassified }\end{array}$ & & $\begin{array}{c}\text { 21. No. of pages } \\
13\end{array}$ \\
\hline
\end{tabular}

"For sale by the National Technical Information Service, Springfield, Virginia 22161 


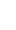


National Aeronautics and

Space Administration

Washington, D.C.

20546

Official Business

Penalty for Private Use, $\$ 300$
Postage and Fees Paid

National Aeronautics and

Space Administration

NASA-451

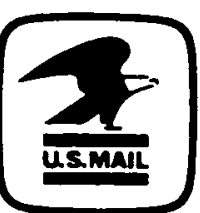

